\title{
Metabolic Processes Preserved as Biosignatures in Iron-Oxidizing Microorganisms: Implications for Biosignature Detection on Mars
}

\author{
Melissa A. Merrill Floyd, ${ }^{1}$ Amy J. Williams, ${ }^{1,2}$ Andrej Grubisic, ${ }^{1}$ and David Emerson ${ }^{3}$
}

\begin{abstract}
Iron-oxidizing bacteria occupy a distinct environmental niche. These chemolithoautotrophic organisms require very little oxygen (when neutrophilic) or outcompete oxygen for access to Fe(II) (when acidophilic). The utilization of $\mathrm{Fe}(\mathrm{II})$ as an electron donor makes them strong analog organisms for any potential life that could be found on Mars. Despite their importance to the elucidation of early life on, and potentially beyond, Earth, many details of their metabolism remain unknown. By using on-line thermochemolysis and gas chromatography-mass spectrometry (GCMS), a distinct signal for a low-molecular-weight molecule was discovered in multiple iron-oxidizing isolates as well as several iron-dominated environmental samples, from freshwater and marine environments and in both modern and older iron rock samples. This GC-MS signal was neither detected in organisms that did not use $\mathrm{Fe}(\mathrm{II})$ as an electron donor nor present in iron mats in which organic carbon was destroyed by heating. Mass spectral analysis indicates that the molecule bears the hallmarks of a pterin-bearing molecule. Genomic analysis has previously identified a molybdopterin that could be part of the electron transport chain in a number of lithotrophic iron-oxidizing bacteria, suggesting one possible source for this signal is the pterin component of this protein. The rock samples indicate the possibility that the molecule can be preserved within lithified sedimentary rocks. The specificity of the signal to organisms requiring iron in their metabolism makes this a novel biosignature with which to investigate both the evolution of life on ancient Earth and potential life on Mars. Key Words: Geomicrobiology-Mars-Pterin cofactor-Biosignature-Iron-oxidizing bacteria-TMSH. Astrobiology 19, 40-52.
\end{abstract}

\section{Introduction}

B IOSIGNATURES ARE ESSENTIAL in the search for life on other worlds and to understand the evolution of life on Earth. Organic biosignatures are an important component of this search, since they can provide robust evidence for biochemical processes only achievable by a living organism. Because organic molecules are labile, most are broken down over time and do not survive either microbial or diagenetic processing. Lipids are an exception, and there is a great deal of research interest in their potential to produce recognizable organic biosignatures that can be extracted from modern to ancient mineral substrates (e.g., Summons et al., 1988; Kaur et al., 2011; Wilhelm et al., 2017). Other biomolecules have received less attention; however, with the development of advanced mass spectrometers and improved extraction techniques there remains the possibility of identifying unique biosignatures indicative of life.

Fe-oxidizing bacteria $(\mathrm{FeOB})$ associated with copious rust-colored precipitates that form in circumneutral Fe-rich waters have been described since the first part of the $19^{\text {th }}$ century, although their status as lithotrophs has only more recently been established (Emerson et al., 2010). Many neutrophilic $\mathrm{FeOB}$ produce unique filamentous extracellular structures such as tubular sheaths or twisted stalks as a result of their growth. These organo-metallic structures provide a mechanism for removal of the iron oxides they produce as a result of their growth to prevent cell encrustation, and also help maintain the cells in their preferred location in opposing gradients of $\mathrm{Fe}(\mathrm{II})$ and $\mathrm{O}_{2}$ (Chan, 2016b; Vesenka et al., 2018). Fortuitously, these biogenic minerals can also become part of the rock record if the iron-oxide fabrics

\footnotetext{
${ }^{1}$ NASA Goddard Space Flight Center, Greenbelt, Maryland.

${ }^{2}$ Department of Physics, Astronomy, and Geosciences, Towson University, Towson, Maryland.

${ }^{3}$ Bigelow Laboratory for Ocean Sciences, East Boothbay, Maine.
}

(C) Melissa A, Merrill Floyd et al., 2018; Published by Mary Ann Liebert, Inc. This Open Access article is distributed under the terms of the Creative Commons Attribution Noncommercial License (http://creativecommons.org/licenses/by-nc/4.0/) which permits any noncommercial use, distribution, and reproduction in any medium, provided the original author(s) and the source are credited. 


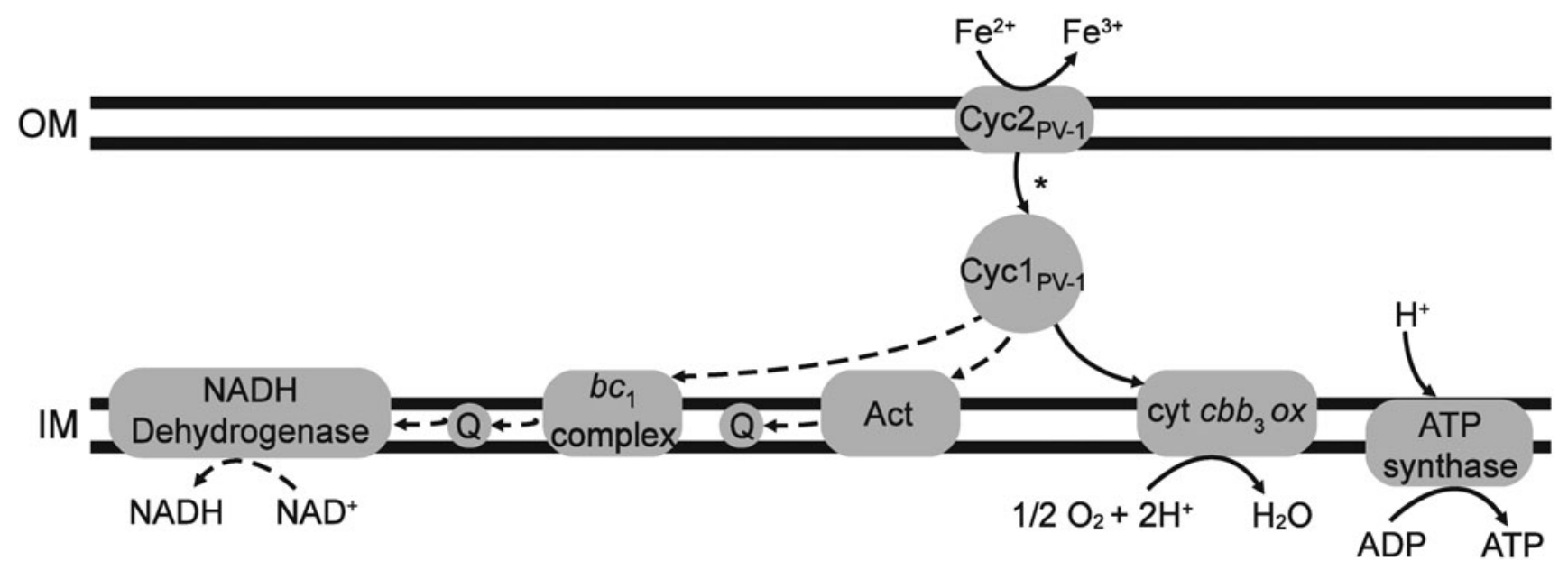

FIG. 1. Electron transport chain of $M$. ferrooxydans as proposed by Barco et al. (2015) based on proteomic analysis. $\mathrm{Act}=$ alternative complex III, $\mathrm{Q}=$ quinone pool, cyt $c b b_{3} o x=$ cytochrome $c b b_{3}$ oxidase, $\mathrm{OM}=$ outer membrane, $\mathrm{IM}=\mathrm{inner}$ membrane. Modified from Barco et al. (2015).

undergo preservation under the right conditions (e.g., tectonically stable environments that prevent physical destruction and chemically nonreactive systems that discourage large-scale iron reduction, e.g., Williams et al., 2015). This makes FeOB one of the few groups of bacteria that can produce a robust, inorganic biosignature (Chan et al., 2016a, 2016b).

Mechanistically, the biochemical pathway for the conservation of energy coupled to the oxidation of iron is still poorly understood. There is consensus that it most likely involves the process of extracellular electron transfer, whereby an electron is captured at the cell surface from the oxidation of $\mathrm{Fe}$ (II) to $\mathrm{Fe}$ (III) and moved to the electron transport chain in the cytoplasmic membrane (Barco et al., 2015) (Fig. 1). Comparative genomics and whole cell proteomics have identified key components of the different complexes of the electron transport chain, and several likely candidates for cytochromes that may be involved in important steps in $\mathrm{Fe}(\mathrm{II})$-oxidation and electron transport (Emerson et al., 2013). It is therefore not known if molecular components of this pathway could produce an organic biosignature that is an indicator of microbial iron oxidation.

We report here the identification of a small-molecularweight organic molecule that is associated with microbial iron mats and pure cultures of lithotrophic FeOB and that has the potential to be extracted directly from iron-mineral substrates. Our study has identified peaks in GC-MS consistent with putative pterin-related fragments in both modern iron-oxidizing isolates and environmental samples, as well as in modern iron rock samples and iron rock samples hundreds to thousands of years old. We propose that the presence of these peaks in this diversity of samples serves as a biosignature for iron-oxidizing organisms.

\section{Materials and Methods}

\subsection{Sample collection and processing}

A variety of biological and geological environmental samples, ranging from freshwater to marine and modern to thousands of years old, were tested for the small-molecularweight fragment that yielded a doublet peak signal (SMW doublet) at 14.2 and $14.7 \mathrm{~min}$ retention time by using the method described in Section 2.4 (Table 1, Fig. 2). Biological modern samples included freshwater iron-oxidizing (Sideroxydans lithotrophicus [ES-1] and Gallionella capsiferriformans [ES-2]) and marine iron-oxidizing (Mariprofundus ferrooxydans [PV-1], Mariprofundus sp. [EKF-1], and Ghiorsea bivora [TAG-1]) isolates, as well as mixed-community environmental samples from freshwater iron-oxidizing microbial mats from Iceland (Jarn), Indiana (iron seeps \#6 and \#7) (Roden et al., 2012), and Spruce Point, Maine (Chan et al., 2016b), respectively. A marine iron-oxidizing microbial mat was collected in 2014 from the Eifuku Seamount on the Mariana forearc (21 29.275N; $1442.524 \mathrm{E} ; 1580$ meters below sea level). In addition, a sulfur-oxidizing mat was collected at a different vent site at Eifuku (21 29.244N, 144 2.485E, 1606 meters below sea level). Non-ironoxidizing isolates were also tested, including Shewanella oneidensis grown both aerobically on complex media and anaerobically as an iron-reducer on ferric citrate, and $\mathrm{Mi}$ crococcus luteus and Bacillus muralis, both isolated from the Yunguay region of the Atacama Desert and grown aerobically on complex media. Strains and culture conditions are described below.

Modern geological samples tested included biogenic schwertmannite (a sulfate-bearing hydrous ferric oxide) rock samples, aged approximately 3 years from sample collection. These samples, labeled SS, were collected in 2012 and 2013 from several sites along a mine water effluent pipeline that runs from a pump station at Old Mine \#8 to an on-site neutralization plant at the Iron Mountain acid mine drainage (AMD) site in California. The pipeline carried $\mathrm{pH}$ 2.5-3.0 AMD, and microbial oxidation of the AMD formed a thick layer of biotically precipitated iron oxyhydroxysulfates (mostly schwertmannite and minor poorly crystalline goethite) (Williams et al., 2017a). These deposits form and lithify on the order of months to years; the samples reported here formed on the order of 6 months to 4 years. The precipitate contained flocculent to lithified schwertmannite with a substantial microbial community present within the precipitate.

Older geological samples consisting of goethite and pyrite rock samples hundreds to thousands of years old were 
Table 1. Small-Molecular-Weight Doublet Signal Detection in Biological and Rock Samples as Tested with TMSH Thermal Desorption GC-MS

\begin{tabular}{|c|c|c|c|}
\hline Sample name & Organism or sample information & $\begin{array}{l}\text { Contains/ed } \\
\text { Fe-oxidizing } \\
\text { organism(s)? }\end{array}$ & $\begin{array}{c}\text { Pterin } \\
\text { cofactor } \\
\text { signal? }\end{array}$ \\
\hline \multicolumn{4}{|l|}{ Biological samples } \\
\hline ES-1 & Isolate Freshwater Sideroxydans lithotrophicus (ATCC 700298) & Yes & Yes \\
\hline ES-2 & Isolate Freshwater Gallionella capsiferriformans (ATCC 700299) & Yes & Yes \\
\hline PV-1 & Isolate Marine Mariprofundus ferrooxydans (ATCC BAA-1021) & Yes & Yes \\
\hline TAG-1 & Isolate Marine Ghiorsea bivora (NCMA B5) & Yes & Yes \\
\hline EKF-1 & Isolate Marine Mariprofundus sp. (accession in progress) & Yes & Yes \\
\hline MR-1 & Isolate Shewanella oneidensis (NCMA B123), grown as a heterotroph & No & No \\
\hline MR-1 & Isolate Shewanella oneidensis (NCMA B123), grown as an iron reducer & No & Yes \\
\hline NF-1 & $\begin{array}{l}\text { Isolate Micrococcus luteus grown as a heterotroph, Yunguay region, } \\
\text { Atacama Desert, Chile (type strain: ATCC 4698) }\end{array}$ & No & No \\
\hline Bmur-1 & $\begin{array}{l}\text { Isolate Bacillus muralis grown as a heterotroph, Yunguay region, Atacama } \\
\text { Desert, Chile (type strain: DSM 16288) }\end{array}$ & No & No \\
\hline JARN-1 & Mixed Community Freshwater Hella, Iceland Iron Seep & Yes & Yes \\
\hline IFS-6 & Mixed Community Freshwater Bloomington, Indiana, USA Iron Seep \#6 & Yes & Yes \\
\hline IFS-7 & Mixed Community Freshwater Bloomington, Indiana, USA Iron Seep \#7 & Yes & Yes \\
\hline $\mathrm{SP} \mathrm{Fe}$ & $\begin{array}{l}\text { Mixed Community Freshwater Spruce Point, Maine, USA microbial mat } \\
\text { with FeOB }\end{array}$ & Yes & Yes \\
\hline Mar. Fe & Mixed Community Marine Marianas Trench microbial mat with FeOB & Yes & Yes \\
\hline Mar. S & $\begin{array}{l}\text { Mixed Community Marine Marianas Trench microbial mat } \\
\text { with sulfur-oxidizing bacteria }\end{array}$ & Likely some & Yes \\
\hline \multicolumn{4}{|c|}{ Geological samples } \\
\hline SS12 & Modern biotic AMD schwertmannite precipitate site 12 & Yes & Yes \\
\hline SS10 & Modern biotic AMD schwertmannite precipitate site 10 & Yes & Yes \\
\hline SS6 & Modern biotic AMD schwertmannite precipitate site 6 & Yes & Yes \\
\hline SS2 & Modern biotic AMD schwertmannite precipitate site 2 & Yes & Yes \\
\hline PS5G & Older AMD goethitic iron gossan rock & Unknown & No \\
\hline PS5P & Older AMD pyritic iron gossan rock & Unknown & Yes \\
\hline \multicolumn{4}{|l|}{ Standards } \\
\hline Pterine-6-COOH & Sigma 2-amino-4-hydroxypteridine-6-carboxylicacid & N/A & Yes \\
\hline Pterine & Sigma 2-amino-4-hydroxypteridine, 2-amino-4-oxodihydropteridine & N/A & Yes \\
\hline Biopterin & Sigma 2-amino-6-(1,2-dihydroxypropyl)-1H-pteridin-4-one standard & N/A & No \\
\hline $\mathrm{FeOH}$ & Sigma FeOH standard & N/A & No \\
\hline
\end{tabular}

collected from the Iron Mountain massive sulfide deposit in California. Iron Mountain, located west of Redding, California, is an oxidizing massive sulfide deposit composed primarily of pyrite and goethite. The massive sulfide deposit formed in a Devonian marine island-arc setting characterized by an extensional, graben-like environment (Albers and Bain, 1985) and has undergone oxidation up through the modern. Although the oxidation has been ongoing for hundreds of millions of years, the age of the gossan is not well constrained. Oxidation of the 20.5 million tons of massive sulfides (pyrite and other sulfides; Alpers et al., 2003) likely took millions of years; therefore, the ages of the gossan samples used in this study are bracketed as "hundreds to thousands of years old." Samples labeled PS were collected in 2010 from the Brick Flat Pit gossan (Albers, 1985), a former open pit mine. PS5P represents a pyritic sample, and PS5G represents a goethitedominated sample (Williams et al., 2015).

Samples had been previously collected (Williams et al., 2015, 2017a) without following organically clean protocols. Therefore, large rock samples from the Iron Mountain gossan were broken open on organically clean ultrahigh vacuum foil with a rock hammer wrapped in ultrahigh vacuum foil to access the uncompromised rock interior. The interior of the rocks was sampled with a solvent-cleaned drill bit and collected into ashed glass vials. AMD pipeline precipitate "SS" samples were collected from service saddles along the pipeline length. Samples were collected with a sterile chisel and placed into acid-washed glass jars, which were stored on ice in the field and in a refrigerator in the laboratory. Subsamples of the pipeline precipitate were sampled with solvent-cleaned tools and collected into ashed glass vials. All rock samples were ground to a fine powder in an ashed mortar and pestle and parsed into aliquots with a solvent-washed scoop in a hood.

\subsection{Strains and culture conditions}

Several pure cultures of $\mathrm{FeOB}$ and non-FeOB were tested for the SMW doublet, and a list of these cultures is shown in Table 1. The FeOB were grown under autotrophic conditions with Fe(II) as electron donor and microaerobically with atmospheres containing approximately $5 \% \mathrm{O}_{2}$ (Emerson and Floyd, 2005). The freshwater FeOB isolates were grown in liquid batch cultures on $\mathrm{FeS}$, while marine FeOB were grown on zero valent iron. Approximately $50 \mathrm{~mL}$ of late log phase of each culture was harvested and concentrated by centrifugation. Cells were grown at room temperature and pressure under microaerophilic conditions. ES-1 was grown in both plastic and glass containers to test 


\section{S. lithotrophicus ES1}

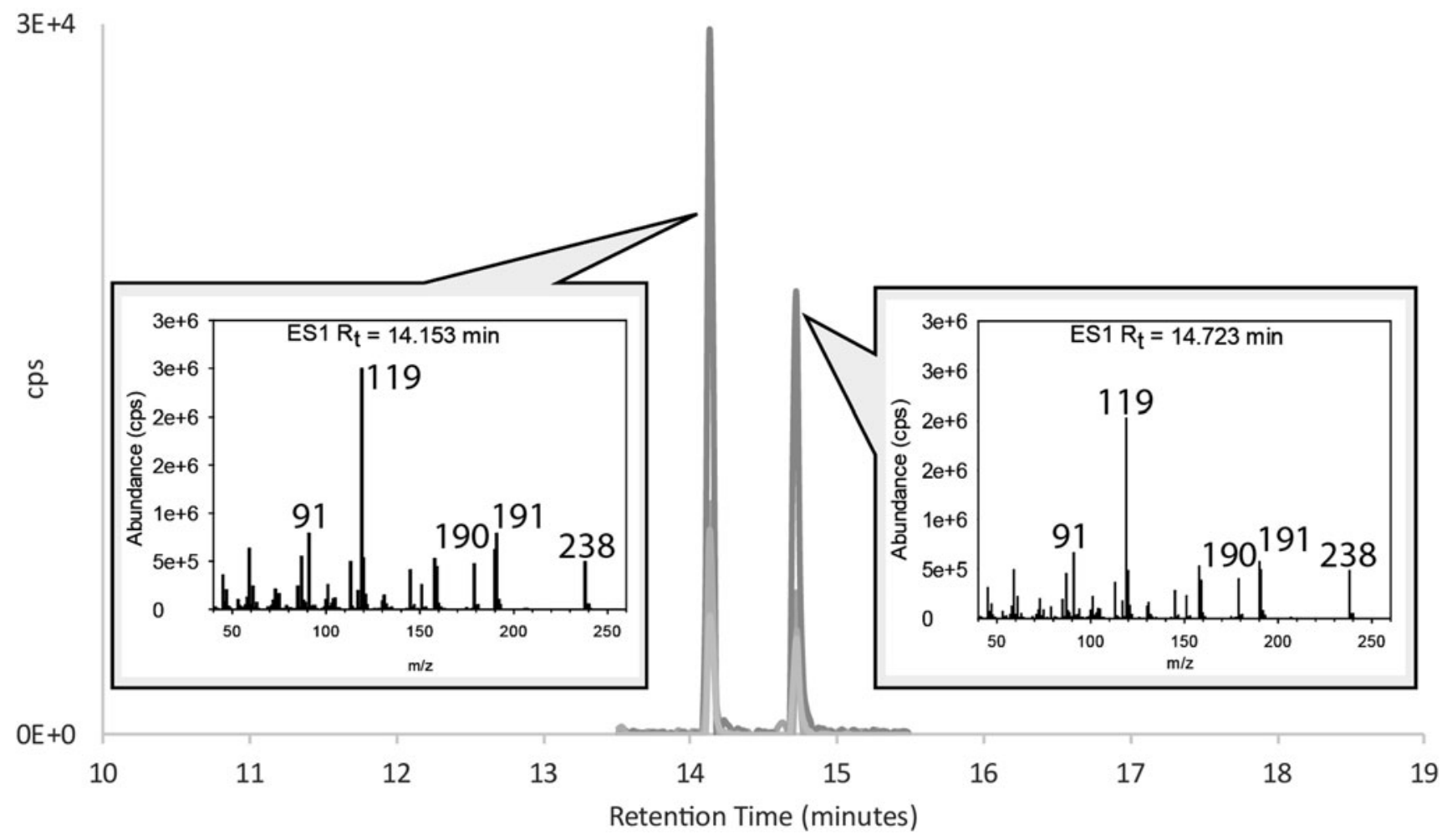

FIG. 2. Combined chromatograph and mass spectra of the SMW doublet peak, at retention times 14.153 and 14.723 min, in iron-oxidizing isolate $S$. lithotrophicus (ES-1). Both peaks contain the following abundant masses: $\mathrm{m} / z=91,119,190,191,238$.

the possibility of potential plastic contamination, of which none was found.

Negative isolate controls (B. muralis [Bmur-1], M. luteus [NF-1], and S. oneidensis [MR-1]) were all heterotrophic isolates grown aerobically on Luria agar. Bacillus muralis and Micrococcus luteus were isolated from soil samples from the Yunguay region of the Atacama Desert in Chile. Shewanella oneidensis MR-1 was grown both heterotrophically under aerobic conditions on Luria agar and anaerobically under ironreducing conditions using ferric citrate as the electron acceptor. The culture was acquired from the National Center for Marine Algae and Microbiota (NCMA B123).

\subsection{Whole cell hydrolysis and methylation}

Conventional analysis entails extensive off-line extraction procedures to liberate organic molecules from the organisms, followed by a derivatization or thermochemolysis step to liberate organic molecules bound in macromolecules and volatilize polar molecules for gas chromatography-mass spectrometry (GC-MS) analysis. The traditional off-line extraction method can be replaced and accelerated with the use of thermally assisted hydrolysis and methylation (THM) driven by pyrolysis or thermal desorption of a whole cell sample in the presence of a methylating agent, such as trimethylsulfonium hydroxide (TMSH) (Ishida et al., 1999; Blokker et al., 2002; Akoto et al., 2005). Other methylating agents such as tetramethylammonium hydroxide (TMAH) or trimethyl phenyl ammonium hydroxide (TMPAH) have also been utilized for THM (Dworzanski et al., 1990; Pel et al., 2004), although they produce known undesirable products, such as the strong degradation and isomerization of fatty acids by highly alkaline TMAH (Jun-Kai et al., 1997; Challinor, 2001). TMSH is a better reagent for on-line methylation, as TMSH requires a lower thermochemolysis temperature, generating fewer pyrolytic side-reactions, and the on-line process produces comparable results to the conventional off-line extraction and methylation procedure (Akoto et al., 2005). Additionally, TMSH is capable of methylating N-heterocycles (Yamauchi, et al., 1979), a fundamental component of pterinbearing molecules.

Based on the expected performance of TMSH with online thermal desorption, this reagent was chosen for direct THM of the biological and geological samples in this study. Three microliters each of the biological samples were dried under $\mathrm{N}_{2}$; the exceptions to this were TAG-1 and EKF-1. Due to higher signal size, only $1 \mu \mathrm{L}$ of each of these was used. Samples then underwent direct THM with TMSH at a ratio of $1 \mu \mathrm{L}$ to between 5 and $9 \mu \mathrm{L}$ of TMSH. Geological samples underwent a similar procedure, with $1 \mathrm{mg}$ of powdered sample to between 5 and $9 \mu \mathrm{L}$ of TMSH. The ratios of 1:5 and 1:9 were determined to yield the highest signal quantified as counts per second.

\subsection{Thermal desorption gas chromatography analysis program}

The samples were analyzed on an Agilent GC-MS instrument coupled to a Gerstel thermal desorption unit (TDU) for direct THM. The Agilent GC-MS instrument was equipped with a $30 \mathrm{~m}$ Restek RTX-5 capillary column with a $0.25 \mathrm{~mm}$ internal diameter and used $\mathrm{He}$ as the carrier gas. The TDU program increased at $16^{\circ} \mathrm{C} / \mathrm{min}$ from $30^{\circ} \mathrm{C}$ to $350^{\circ} \mathrm{C}$. The 
oven program utilized three heating ramps to separate molecules: (1) increase at $30^{\circ} \mathrm{C} / \mathrm{min}$ from $70^{\circ} \mathrm{C}$ to $120^{\circ} \mathrm{C}$, (2) increase at $5^{\circ} \mathrm{C} / \mathrm{min}$ from $120^{\circ} \mathrm{C}$ to $250^{\circ} \mathrm{C}$, and (3) increase at $6^{\circ} \mathrm{C} / \mathrm{min}$ from $250^{\circ} \mathrm{C}$ to $320^{\circ} \mathrm{C}$. Compound identification was completed with the ChemStation software and was based on retention times, mass spectral analysis, and comparison with pterin compound standards 6-biopterin (2-amino-4-hydroxy6-(1,2-dihydroxypropyl)pteridine), pterine-6-carboxylic acid (2-amino-4-hydroxypteridine-6-carboxylicacid), and pterine (2-amino-4-hydroxypteridine, 2-amino-4-oxodihydropteridine) when reacted with TMSH (all standards from Sigma-Aldrich). An organically clean $\mathrm{FeOH}$ powder (Sigma-Aldrich) was also reacted with TMSH to quantify any signal input from the presence of iron oxides.

\section{Results}

\subsection{Signal detection in $\mathrm{FeOB}$ isolates, environmental samples, and microbial mats}

The SMW doublet signal discussed here was initially identified by using in situ whole cell thermal desorption derivatization and GC-MS. A low-molecular-weight pair of successive peaks and identical mass spectra with retention times of $c a .14 .2$ and $14.7 \mathrm{~min}$ (Fig. 2) was discovered in both pure cultures of $\mathrm{FeOB}$ and in mixed community freshwater and marine environmental samples that contain FeOB. They were also present in natural, actively growing microbial iron mats from all the sampled freshwater and marine sources. These peaks were absent from the heterotrophic bacterial isolates (B. muralis, M. luteus, and S. oneidensis) (Fig. 6).

The metabolically flexible $S$. oneidensis was grown under different metabolic conditions to determine if the signal was related more broadly to iron metabolism (in this case, iron reduction). Interestingly, when the Fe reducer $S$. oneidensis was grown aerobically on complex heterotrophic media, no SMW doublet signal was observed; however, when it was grown under Fe-reducing conditions with ferric citrate as the electron acceptor, the SMW doublet signal was observed (Fig. 3), although it was significantly reduced. The possibility that the iron-oxidation pathway can be reversed for the purpose of iron reduction has been explored (Ilbert and Bonnefoy, 2013), and it is possible that the putative pterinbearing molecule required for iron oxidation can also be found in the reductive pathway. This unexpected result suggests that iron metabolisms in general may utilize proteins that require this particular putative pterin-cofactor, making this metabolic biosignature applicable to the detection of both iron-oxidizing and iron-reducing organisms.

From the biological and geological samples tested, every sample that was known to contain FeOB also yielded the SMW doublet signal in GC-MS (Table 1). From the biological samples, these included modern freshwater and marine iron-oxidizing isolates, as well as freshwater and marine mixed community environmental samples.

The structure of the freshwater iron mat from Spruce Point was dominated by the sheath-producing FeOB related to Leptothrix ochracea, although a number of other clades of lithotrophic FeOB are present as well (Chan et al., 2016b). The fresh iron mat elicited a strong SMW doublet signal in GC-MS; however, the same signal was absent from mat material that was heated at $425^{\circ} \mathrm{C}$ for $2 \mathrm{~h}$ to combust organic matter (Fig. 4). Two microbial mats from a hydrothermal vent near the Marianas Trench were also compared to search for the SMW doublet signal. One mat was irondominated and contained abundant FeOB, whereas the other mat was sulfur-dominated and had few if any FeOB. The iron mat contains several clades of marine FeOB belonging to the Zetaproteobacteria, while the S-mat was instead dominated by sulfur-oxidizing Epsilonproteobacteria (C. Moyer, personal communication). The iron mat yielded a strong signal, while only a weak signal was observed in the sulfur mat (Fig. 5).

All non-iron-oxidizing biological samples grown as aerobic heterotrophs on complex media failed to yield the SMW doublet signal in GC-MS.

\subsection{Signal detection in modern \\ and older rock samples}

The SMW doublet signal was discovered in a suite of modern AMD iron precipitates with an extant FeOB community, as well

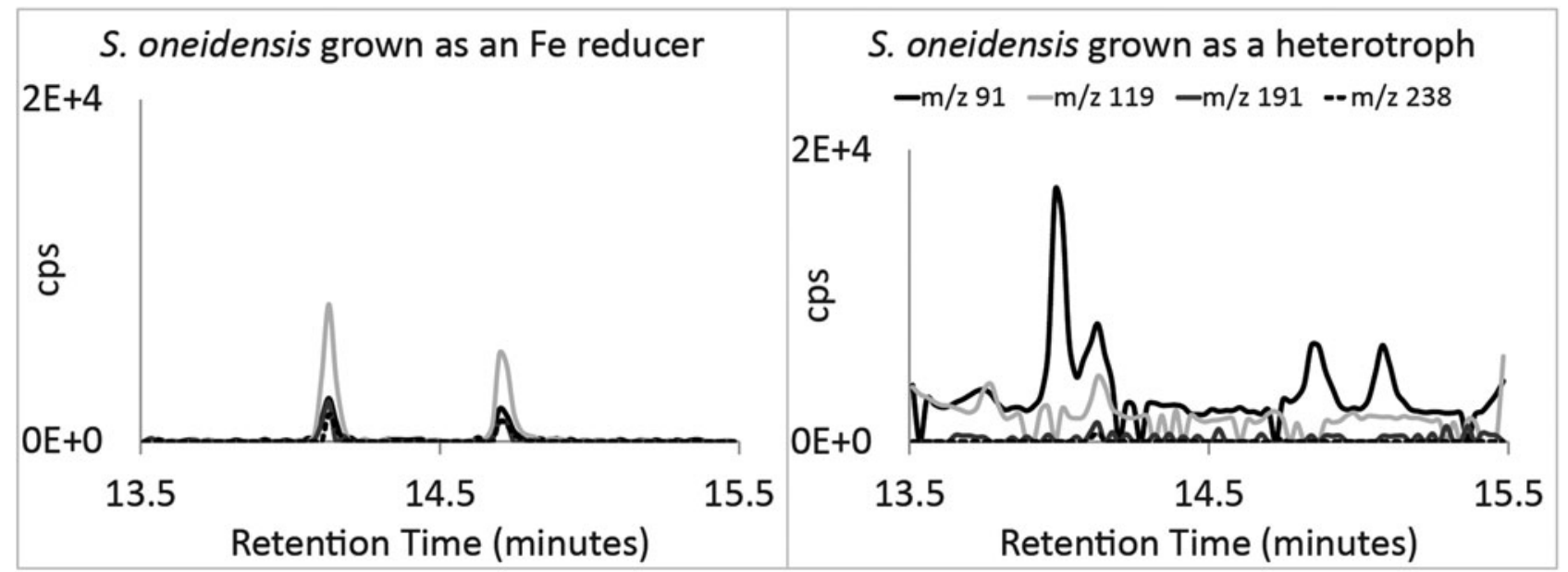

FIG. 3. Sample normalized SMW doublet peak detection comparison between S. oneidensis grown as an iron reducer and grown as a heterotroph. The culture grown on ferric citrate under iron-reducing conditions yielded a clear and well-defined signal, whereas the signal was absent from the culture grown heterotrophically. 


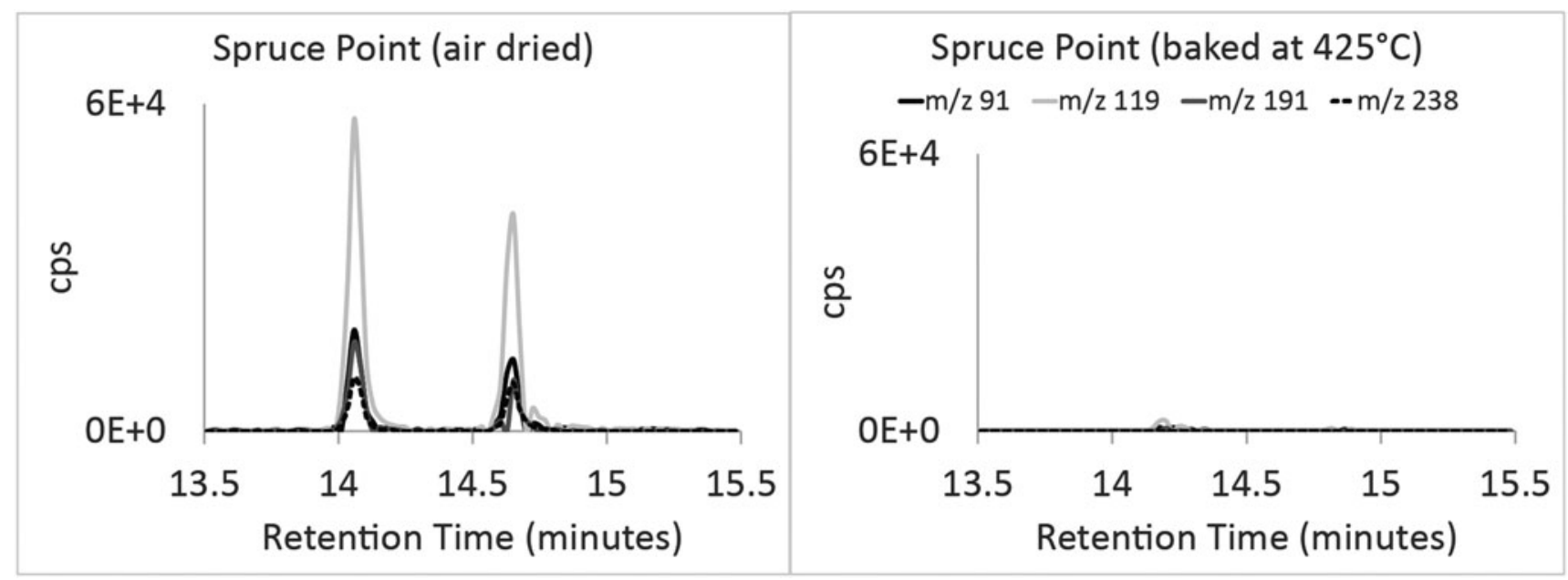

FIG. 4. Sample normalized SMW doublet peak detection comparison between a Spruce Point iron mat subsample that was air-dried in sterile conditions and a subsample that was baked at $425^{\circ} \mathrm{C}$ for 22 hours. Peaks are well formed in the airdried sample and nonexistent in the baked sample, indicating degradation of the peak-molecule at elevated temperatures.

as in a pyritic gossan sample hundreds to thousands of years old (Fig. 6). The $m / z=91,119,191$, and 238 signal was strongest in the modern schwertmannite AMD iron precipitates, with the signal intensity decreasing from sample $\mathrm{SS} 10>\mathrm{SS} 6>\mathrm{SS} 2>$ SS12. The most upstream sample is SS12, and sample numbering decreases downstream to SS2. Biomass concentrations are highest near SS12 and decrease downstream (Campbell et al., 2013b). Although the signal is most elevated at SS10 and decreases downstream to SS2, the lowest signal at SS12 indicates that the signal is not necessarily dependent upon the volume of biomass in the system and may be dependent on multiple factors including the presence of specific organisms that utilize the cofactor associated with iron metabolisms.

The modern biotic schwertmannite precipitate is known to contain FeOB (Williams et al., 2017a), and those SS samples yielded the SMW doublet signal in GC-MS. Of the older gossan samples, the PS5G goethitic sample did not yield the SMW doublet signal in GC-MS, and it is unknown whether the goethitic sample contains or contained $\mathrm{FeOB}$ specifically, although geobiological evidence indicates that microbial communities were present during various stages of gossan formation (Williams et al., 2015). The PS5P pyritic sample did yield the SMW doublet signal in GC-MS, and although it is unknown whether the pyritic sample contains or contained FeOB specifically, it is highly likely that FeOB would exploit a pyritic surface, under either acidic or circumneutral pH (Edwards et al., 1999; Havig et al., 2017).

The signal was weaker but readily detected in the PS5P pyritic gossan sample, while no signal was detected in the PS5G goethitic gossan sample. Although the pyritic sample was collected from the interior of a residual pyrite nodule tens of centimeters wide, the gossan rock was highly fractured in situ, and it is possible that this SMW doublet signal identifies a modern microbial incursion of iron-oxidizing organisms onto the pyrite. The oxidation of pyrite to goethite in the

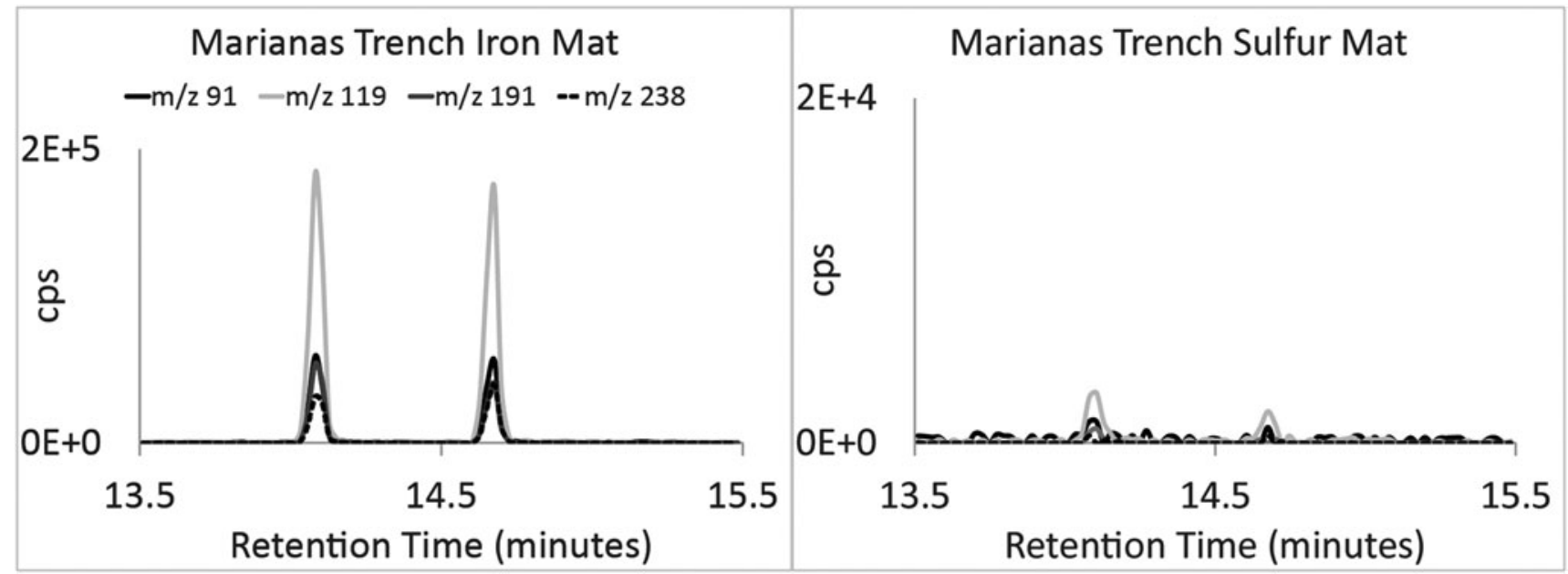

FIG. 5. Sample normalized SMW doublet peak detection comparison between two microbial mat samples from a hydrothermal vent near the Marianas Trench. The iron-dominated mat with marine Zetaproteobacteria FeOB communities yielded clear and well-formed peaks, whereas the sulfur-dominated mat with sulfur-oxidizing Epsilonproteobacteria communities yielded very weak and poorly formed peaks. These peaks may be explained by the presence of few FeOB within the otherwise SOB-dominated mat. 


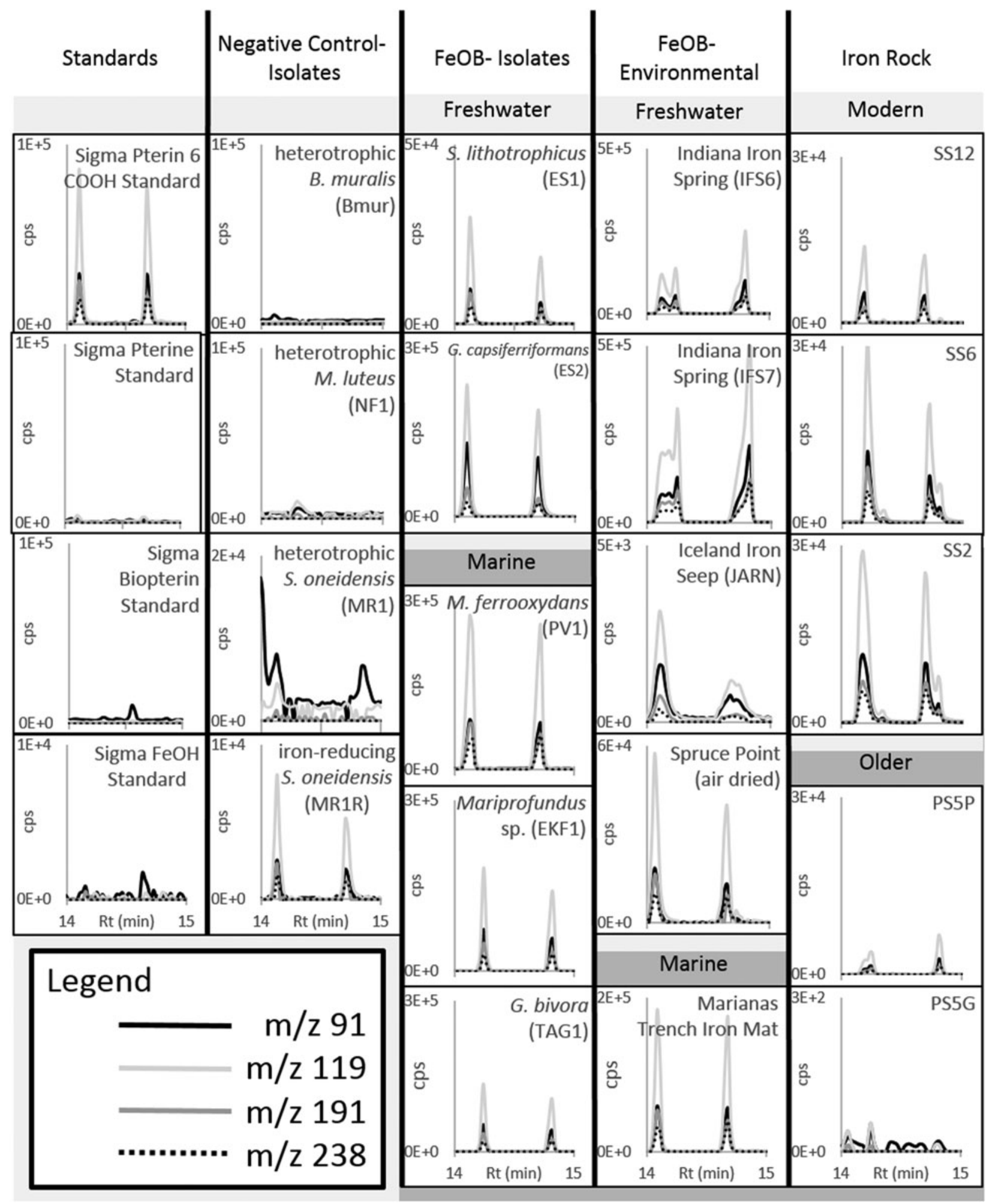

FIG. 6. Comparison of sample mass or volume normalized putative pterin-cofactor peak detection in pterin-bearing standards, isolate negative controls and non-FeOB controls, FeOB isolates from freshwater and marine systems, environmental samples with FeOB communities from freshwater and marine systems, and modern biogenic sulfate-bearing hydrous ferric oxides and pyrite and goethite gossan samples hundreds to thousands of years old. 
Iron Mountain gossan proceeds both biotically and abiotically (Alpers et al., 2003; Williams et al., 2015). The GCMS signal of interest was initially expected in the goethitic sample, as $\mathrm{FeOB}$ communities likely participated in the formation of the goethite and $\mathrm{FeOB}$ cellular membranes may have been preserved in the goethite-precipitation process. It is possible that the SMW doublet signal was (1) not initially present, (2) not preserved at all during the acidic gossanforming processes, or (3) initially preserved but then degraded over the past hundreds to thousands (or more) years and is no longer detectable, if it was initially present.

\subsection{Signal detection in pterin chemical standards}

Four Sigma-Aldrich pterin standards were reacted with TMSH and analyzed with thermal desorption GC-MS. Of these standards, the pterine-6-carboxylic acid and pterine standards yielded the SMW doublet signal in GC-MS, while the signal was absent from the 6-biopterin and $\mathrm{FeOH}$ standards.

Table 1 reports the presence or absence of the SMW doublet signal, but the relative intensity of the signal when present varies between samples (Fig. 6). Signal intensity, reported as counts per second, is normalized to sample mass or volume in Fig. 6 and Table 2 to show the relative intensity of each sample in this study. In general, the marine samples yielded higher signal intensities than the freshwater samples, with the notable exception of the Indiana

\begin{tabular}{llc}
\multicolumn{2}{c}{$\begin{array}{c}\text { TABLE 2. NORMALIZED } M / Z=119 \text { SigNAL INTENSITY } \\
\text { REPORTED AS COUNTS PER SECOND (CPS) }\end{array}$} \\
\hline Environment & \multicolumn{1}{c}{ Sample } & $\begin{array}{r}\text { Normalized } \\
\text { maximum CPS }\end{array}$ \\
\hline Freshwater & IFS-7 & 539819 \\
Marine & PV-1 & $\mathbf{2 7 4 5 3 9}$ \\
Freshwater & IFS-6 & 250112 \\
Marine & Marianas Fe Mat & $\mathbf{2 2 0 2 6 7}$ \\
Marine & EKF-1 & $\mathbf{1 8 2 6 5 6}$ \\
Marine & TAG-1 & $\mathbf{1 3 6 0 0 0}$ \\
Standard & Pterine-6-COOH & 108495 \\
AMD & SS10 & 67587 \\
Freshwater & ES-2 & 62741 \\
Freshwater & Spruce Pt. & 52437 \\
& Fe Mat air-dried & \\
AMD & SS6 & 31127 \\
Freshwater & ES-1 & 29459 \\
AMD & SS2 & 29178 \\
AMD & SS12 & 13638 \\
Iron Reducer & MR-1R & 8040 \\
Control & & \\
AMD & PS5P & 6708 \\
Standard & Pterine & 4251 \\
Freshwater & JARN-1 & 3133 \\
Marine & Marianas S Mat & $\mathbf{2 9 0 8}$ \\
Negative Control & MR-1 & 0 \\
Negative Control & NF-1 & 0 \\
Negative Control & Bmur-1 & 0 \\
Freshwater & Spruce Pt. Fe Mat & 0 \\
& $425^{\circ}$ C & 0 \\
AMD & PS5G & 0 \\
Standard & Biopterin & 0 \\
Standard & FeOH & \\
\hline & &
\end{tabular}

Marine samples are bolded. Freshwater samples are italicized.
Iron Seep, not Spring samples (IFS-7 and IFS-6), which yielded the highest and third-highest signal intensities, respectively.

\section{Discussion}

\subsection{Evidence for a pterin cofactor from the small molecular weight doublet signal}

The SMW doublet signal consisted of two successive peaks that consistently eluted at $c a .14 .2$ and 14.7 minutes using the thermal desorption and GC programs described above. The highest-abundance masses in both peaks occurred at $\mathrm{m} / \mathrm{z} 91$, 119, 191, and 238. These masses were not present in the negative control samples (Fig. 7). These peaks had nearly identical mass spectra, possibly indicating the presence of one or more locations on the molecule with more than one isomeric conformation. The $m / z, 91$ indicated that a ring structure was present, and the $m / z, 59$ indicated a likely carboxylic acid moiety as a side chain on the ring structure. The spectra for both successive peaks exhibited odd $\mathrm{M}$ values, indicating that an odd number of nitrogen atoms were present in the structure. This is consistent with the ability of TMSH to methylate N-heterocycles (Yamauchi, et al. 1979). Based on this consistent pattern of masses, as well as the presence of the molybdopterin oxidoreductase ( $a c t B)$-containing gene cluster in most $\mathrm{FeOB}$ genomes, the hypothesis that the fragment could contain or be a pterin was further explored.

To test this hypothesis, several Sigma-Aldrich pterin standards (Fig. 8) were analyzed via GC-MS. 6-Biopterin (2-amino-4-hydroxy-6-(1,2-dihydroxypropyl)pteridine) did not display the characteristic masses that comprised the pterinfragment signature from the $\mathrm{FeOB}$ and $\mathrm{FeOB}$-containing environmental samples. Pterine (2-amino-4-hydroxypteridine) showed some similarities, specifically signals at $m / z$ 91, 119 , and 239 , although the signal strength was considerably weaker and the patterns of those masses did not match the $\mathrm{FeOB}$ putative-pterin fragment closely. The pterine-6-carboxylic acid (2-amino-4-hydroxypteridine-6-carboxylicacid) showed a striking similarity to the $\mathrm{FeOB}$ pterin fragment, with all four peaks of interest present and generally consistent in abundance (Fig. 9).

\subsection{Source of the putative pterin-cofactor molecule}

Pterins consist of a group of highly conserved molecules that contribute to many different functions in organisms from all three domains of life. The fundamental components of a pterin include fused pyrimidine and imidazole rings that form a nitrogen heterocycle with five nitrogens within the two rings, and the pyrimidine ring contains both amino and keto functional group substitutions.

Pterins are important cofactors in molybdenum-containing enzymes that are typically redox active in cells. The most well-known class of these molecules belongs to the molybdopterins, also referred to as pyranopterins, which are proteins that contain molybdenum complexed with a pterin that produces an active site. Although guanosine triphosphate (GTP) is the precursor molecule for all pterins, molybdopterin is synthesized from GTP via a specific pathway independent from those used to synthesize pterins such as neopterin, biopterin, and monapterin (Feirer and Fuqua, 2017). Although the nucleobase guanine can have a similar structure to the molecule of interest described here, and although the 


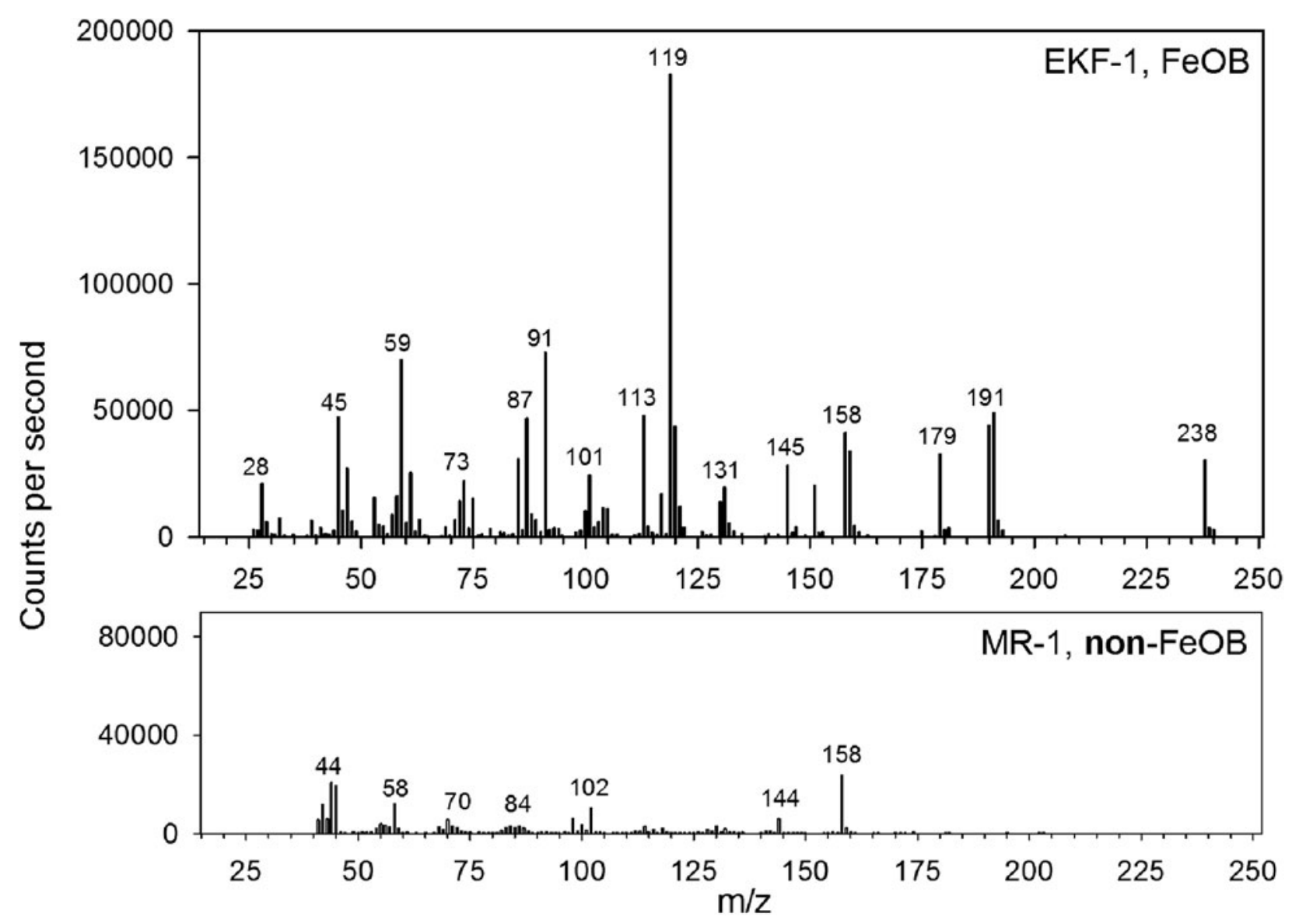

FIG. 7. Comparison of mass spectra from an FeOB isolate, EKF-1, and the negative control S. oneidensis grown as a heterotroph. The masses of interest in the FeOB sample are $m / z, 91,119,191$, and 238, and are present in much higher abundances in the FeOB-bearing samples tested.

biosynthesis of molybdopterin is initiated from GTP, the mass spectrum of guanine and its methylated counterpart demonstrates that the molecule of interest is quite different from these nucleobases (Supplementary Fig. S1, available online at www.liebertonline.com/ast). Molybdopterin enzymes are involved in oxidation reactions and belong to three different families, represented by the enzymes xanthine oxidase, sulfite oxidase, and dimethysulfoxide (DMSO) oxidoreductase, respectively (Feirer and Fuqua, 2017). It was previously noted that a majority of the genomes from FeOB (both freshwater and marine) contained the molybdopterin oxidoreductase $(a c t B)$-containing gene cluster recognized as the alternative complex (AC) III (Singer et al., 2011; Refojo et al., 2012). It is important to note that the most well characterized examples of the AC III proteins in Rhodothermus and Chloroflexus do not actually contain Mo and may lack pterins. The cognate proteins in the FeOB have not been purified or carefully studied, so it is not known if they do or do not have pterin moieties. Nonetheless, genomic analysis of all the FeOB isolates used in this study does show the genetic potential to produce pterins and to take up molybdenum, indicating they likely do have some type of molybdopterin present. Furthermore, proteomic analysis has demonstrated the active expression of these proteins in M. ferrooxydans PV-1 (Barco et al., 2015) and G. bivora TAG-1 (R. Barco, unpublished results). The fact that this molecule is detected in all the pure
FeOB cultures and in the iron mats suggests that these proteins are likely to be actively expressed, in relatively high abundance, and playing an important role in Fe oxidation.

\subsection{Potential for the detection of metabolic biosignatures}

The putative pterin that produces these signals is hypothesized to be part of a membrane-bound protein complex-the AC III of the electron transport chain (Refojo et al., 2012). The power of on-line thermal desorption with TMSH is that TMSH is capable of whole-cell thermochemolysis (as is the similar but more strongly alkaline reagent TMAH), breaking macromolecules such as cellular membranes to volatilize molecules within the membrane (Grasset et al., 2002; Shadkami and Helleur, 2010) such as proteins and fatty acids (Williams et al., 2017b). The putative pterin that produces the SMW doublet signal is vital to the iron oxidation pathway in microbes, and therefore this unique putative pterin signal serves as a metabolic biosignature for modern iron-oxidizing organisms.

Intriguing results suggested that this signal may be indicative of iron metabolism as a whole, rather than just iron oxidation. To test this hypothesis, S. oneidensis MR-1 was grown as an iron reducer with ferric citrate as the electron acceptor. While the putative pterin signal was significantly reduced, it was detected in GC-MS, while the same organism 
<smiles>Nc1nc2ncc(C(=O)O)nc2c(=O)[nH]1</smiles><smiles>Nc1nc(O)c2nccnc2n1</smiles>

C 6-biopterin<smiles>C[C@H](O)[C@H](O)C1=NC2C(=O)NC(N)=NC2N=C1</smiles><smiles>Nc1nc2[nH]cnc2c(=O)[nH]1</smiles>

FIG. 8. Molecule structures of the pterin-bearing molecules tested in this study, as well as the pterin precursor: (a) pterine-6-carboxylic acid structure, (b) pterine structure, (c) 6-biopterin structure, and (d) guanine structure.

grown aerobically on a complex heterotrophic medium displayed no putative pterin signal at all. The genome of MR-1 does not contain an AC III or a homolog to the $a c t B$ gene, based on analysis using the Joint Genome Institute's integrated microbial genomes (IMG) platform (https://img.jgi.doe.gov), such as those that are discussed above as a possible source of a pterin-like molecule in the FeOB. It has been shown that genes involved in molybdenum cofactor synthesis that include a pterin component are up-regulated in MR-1 cells grown on Fe(III) (Beliaev et al., 2002) There is the possibility that the iron-oxidation pathway can be reversed for the purpose of iron reduction, as has been previously explored (Ilbert and Bonnefoy, 2013), and it is possible that the pterin-bearing molecule required for iron oxidation can also be found in the reductive pathway. Future analyses will test additional organisms, especially obligatory iron reducers, to explore this exciting possibility.

We extended these analyses to include a modern iron precipitate, composed of schwertmannite formed and lithified on the order of months to years within an AMD pipeline (Williams et al., 2017a). These precipitates are known to contain a modern acidophilic microbial community, including iron-oxidizing organisms (Campbell et al., 2013a, 2013b). The putative pterin signal was detected in all tested modern precipitate samples. These results suggest that this signal may be a stable biogenic molecular marker in iron oxides. Thermodynamically, organic molecules are unstable over geological timescales in the presence of iron oxides (Sumner, 2004). However, recent research suggests that under specific conditions, organics may be pre- served over longer timescales in concert with iron oxides (Lalonde et al., 2012; Parenteau et al., 2014; Potter-McIntyre et al., 2014, Hays et al. 2017). Relevant future research will test older iron oxides for the presence of the putative pterin cofactor signal to determine how far back in geological time the signal might be preserved. If preserved into the ancient, this approach provides an exciting opportunity to track the metabolism of ironmetabolizing organisms in both ancient terrestrial and martian rocks.

In an effort to begin to gauge the impact of the effects of geological time on the molecule in question, we also tested two dried Fe mat samples from Spruce Point, Maine, USA. The first was air-dried at room temperature and pressure for $24 \mathrm{~h}$. The second was dried at $475^{\circ} \mathrm{C}$ for $22 \mathrm{~h}$. The FeOB biomarker signal made an appearance in the former signal but not the latter (see Fig. 6), leading to an initial impression that the molecule can be disrupted or destroyed by high heat. Much additional testing would be required to provide more substantial data.

A highly relevant test of the presence of this biomarker and its link to select metabolisms is in environmental samples. The comparison of a marine iron-oxidizing microbial mat to a marine sulfur-oxidizing microbial mat showed a substantially larger signal for the putative pterin peaks in the iron mat. The microbiomes of these two mats are quite different, sharing few abundant taxa in common (C. Moyer, personal communication), and $\mathrm{S}$ metabolism proceeds by a different biochemical pathway than Fe metabolism, although there are microbes that can utilize both $\mathrm{Fe}$ and $\mathrm{S}$ metabolisms. The differential detection via GC-MS discussed here illustrates the potential power for a biosignature to discriminate between different metabolisms and could add an organic analytic capability to the detection of Fe-metabolizing communities, which already include unique morphological and phylogenetic attributes. This could be especially exciting for ancient samples where good preservation of FeOB microfossils is well documented, but there is a lack of diagnostic organic signatures.

\subsection{Utility of peaks as a biosignature in missions to other worlds}

Currently, the Sample Analysis on Mars instrument on the Mars Science Laboratory rover Curiosity can use $N$-tert-butyldimethylsilyl- $N$-methyltrifluoroacetamide with $\mathrm{N}$ - $\mathrm{N}$-dimethylformamide (MTBSTFA/DMF) or tetramethylammonium hydroxide (TMAH in $\mathrm{MeOH}$ ) with GC-MS to silylate or methylate organic molecules, making them detectable to GC-MS and fundamentally changing the way habitability potential is assessed on the Red Planet (Ming et al., 2014). Recent studies have indicated that Mars does host habitable environments (Grotzinger et al., 2014), and it is possible that Fe metabolism could play a vital role as a bioavailable energy source (Bristow et al., 2015).

TMAH was not capable of detecting the putative pterin fragment and so was unsuitable for the purposes of this research. Preliminary investigations of the putative pterin fragment using MTBSTFA as a derivatization agent showed a replicable pattern in both chromatographs and mass spectra (data not shown); however, the information contained in the spectra was less helpful in elucidating the structure of the molecule in question.

This research demonstrates the utility of TMSH as a potential new tool in the search for biosignatures on other 

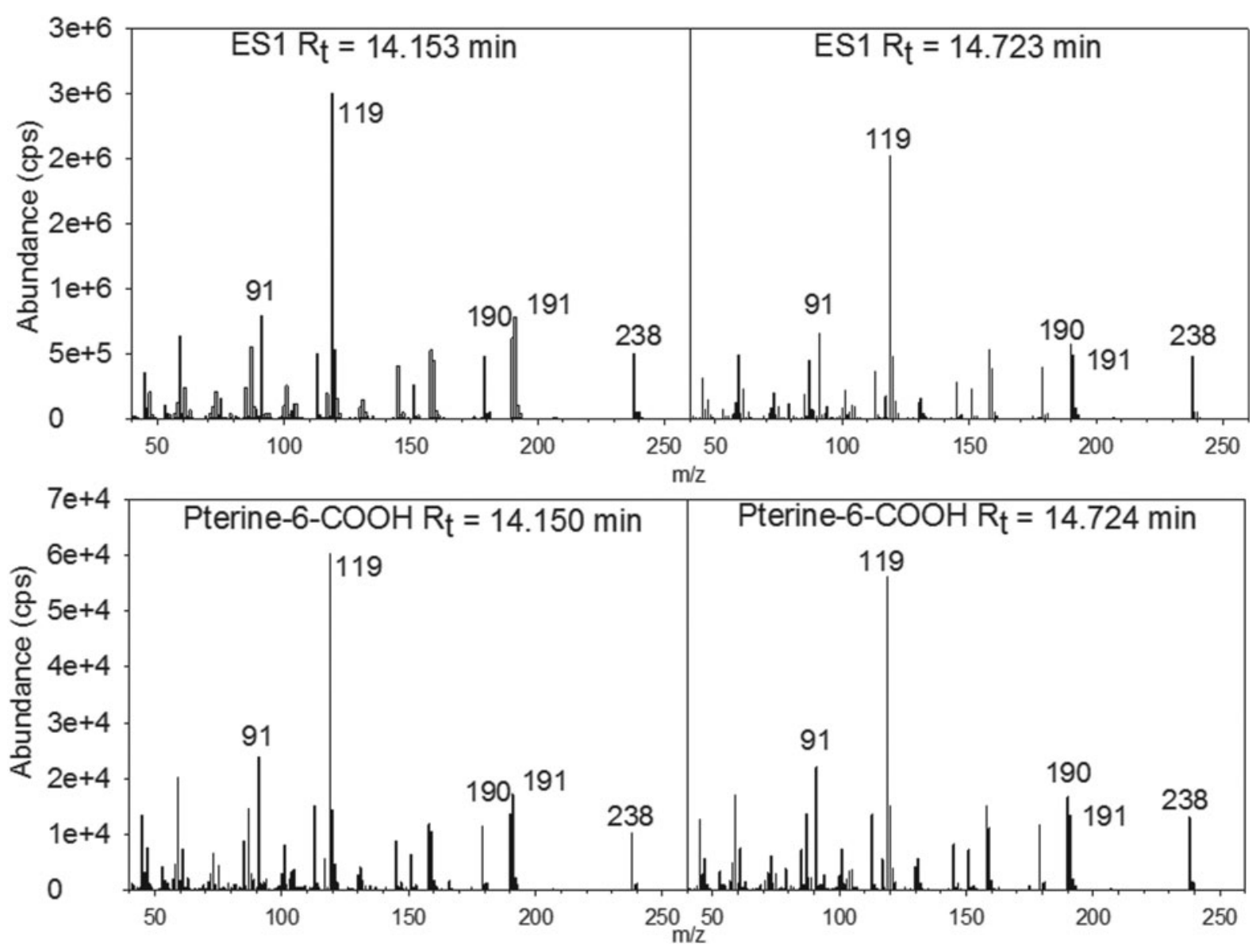

FIG. 9. Comparison of the doublet peaks of interest at retention times 14.15 and 14.72 min in iron-oxidizing isolate $S$. lithotrophicus $(3 \mu \mathrm{L} \mathrm{ES}-1+15 \mu \mathrm{L}$ TMSH) and in the pterine-6-COOH standard (2.445 mg pterine-6-COOH $+18 \mu \mathrm{L} \mathrm{TMSH})$. All peaks contain the same abundant masses: $m / z=91,119,190,191,238$.

planets. It is easily detectable by instruments already proven on spaceflight missions. It does not have interfering background peaks that have proven problematic on current missions. Perhaps most importantly, TMSH represents an opportunity to search for a new class of biosignature, one that represents biological activity and redox chemistry.

\section{Conclusions}

By using in situ thermal desorption derivatization and GCMS, with TMSH as the methylating agent, a strong, replicable signal linked to microbial iron-oxidation has been discovered in the form of a low-molecular-weight pair of successive peaks and identical mass spectra with retention times of $c a$. 14.2 and $14.7 \mathrm{~min}$. Analysis of the mass spectra showed the highest-abundance masses occurred at $m / z=91,119,191$, and 238. These dominant masses and the probable presence of a carboxylic acid moiety at $m / z=59$ indicate a pterin fragment or pterin-bearing molecule, which is in line with the current thinking on the details of the electron-transport chain for these organisms (Ilbert and Bonnefoy, 2013). This chromatographic and spectral pattern was seen in all samples known to contain $\mathrm{FeOB}$ (freshwater and marine FeOB isolates, freshwater and marine environmental samples, modern iron oxide samples, and iron gossan samples) as well as in one sample of $S$. oneidensis MR-1 grown under iron-reducing conditions. This pattern was neither observed in isolates grown heterotrophically nor with those organisms not able to use iron as an electron donor or acceptor.

A signature from such a defined metabolism offers a path forward for identifying FeOB in modern and subrecent environments without the need for genetics-based identification, and also offers a novel biosignature to search for potential microbial life on other worlds. Use of TMSH as a derivatization agent on future robotic missions to other worlds would allow for a new class of organic signals to be detected and analyzed.

Future research on this potential biosignature includes the use of HPLC and NMR to finalize the structure of the molecule in question (e.g., Nisshanthini et al., 2015). Additionally, other isolates should be tested to resolve the boundaries of this biosignature with regard to extracellular iron-metabolism. These include acidophilic FeOB isolates, obligate iron-reducing bacteria (FeRB), sulfur-oxidizing isolates and bacteria that can use both $\mathrm{S}$ and $\mathrm{Fe}$ as electron donors, grown in different media. Testing MR-1 grown anaerobically in defined media with an alternative electron receptor to iron would help circumscribe the reach of the putative pterin signature. Testing ancient rocks, including samples from Archean-aged banded iron formations, would imply how far back in geological time the signal can be preserved and detected and would also give an indication of the preservation potential of the molecule and whether it would likely be detected in the harsh conditions of other planets. 


\section{Acknowledgments}

We would like to thank Mary Beth Wilhelm of NASA Ames Research Center for the Atacama Desert samples and Eric Roden of the University of Wisconsin for the samples from the Indiana iron seeps. This research was supported by the Sample Analysis at Mars (SAM) Project. D. Emerson was supported in part by NASA Exobiology grant NNX15AM11G; sample collection at the Mariana was made possible by NSF grant OCE-1155754 to D. Emerson.

\section{References}

Akoto, L., Pel, R., Irth, H., Brinkman, U.A.T., and Vreuls, R.J.J. (2005) Automated GC-MS analysis of raw biological samples: application to fatty acid profiling of aquatic microorganisms. J Anal Appl Pyrolysis 73:69-75.

Albers, J.P. (1985) Geology of the Brick Flat massive sulfide body, Iron Mountain cluster, West Shasta district, California (USA). Econ Geol 80:2092-2099.

Albers, J.P. and Bain, J.H.C. (1985) Regional setting and new information on some critical geologic features of the West Shasta district, California (USA). Econ Geol 80:2072-2091.

Alpers, C.N., Nordstrom, D.K., and Spitzley, J. (2003) Extreme acid mine drainage from a pyritic massive sulfide deposit: the Iron Mountain end-member. In Environmental Aspects of Mine Wastes, Short Course 31, Mineralogical Association of Canada, Ottawa, pp 407-430.

Barco, R.A., Emerson, D., Sylvan, J.B., Orcutt, B.N., Jacobson Meyers, M.E., Ramírez, G.A., Zhong, J.D., and Edwards, K.J. (2015) New insight into microbial iron oxidation as revealed by the proteomic profile of an obligate iron-oxidizing chemolithoautotroph. Appl Environ Microbiol 81:5927-5937.

Beliaev, A., Thompson, D.K., Khare, T., Lim, H., Brandt, C.C., Li, G., Murray, A.E., Heidelberg, J.F., Giometti, C.S., Yates, J., III, Nealson, K.H., Tiedje, J.M., and Zhou, J. (2002) Gene and protein expression profiles in Shewanella oneidensis during anaerobic growth with different electron acceptors. Omics 6:39-60.

Blokker, P., Pel, R., Akoto, L., Brinkman, U.A.T., and Vreuls, R.J.J. (2002) At-line gas chromatographic-mass spectrometric analysis of fatty acid profiles of green microalgae using a direct thermal desorption interface. J Chromatogr A 959:191-201.

Bristow, T.F., Bish, D.L., Vaniman, D.T., Morris, R.V., Blake, D.F., Grotzinger, J.P., Rampe, E.B., Crisp, J.A., Achilles, C.N., Ming, D.W., Ehlmann, B.L., King, P.L., Bridges, J.C., Eigenbrode, J.L., Sumner, D.Y., Chipera, S.J., Moorokian, J.M., Treiman, A.H., Morrison, S.M., Downs, R.T., Farmer, J.D., Des Marais, D., Sarrazin, P., Floyd, M.M., Mischna, M.A., and McAdam, A.C. (2015) The origin and implications of clay minerals from Yellowknife Bay, Gale Crater, Mars. Am Mineral 100:824-836.

Campbell, K., Alpers, C., Nordstrom, D., Blum, A., and Williams, A. (2013a) Biogeochemical processes involved in formation of schwertmannite-rich scale in a pipeline carrying acid mine drainage at Iron Mountain Mine, California. Geological Society of America Abstracts with Programs 45:287.

Campbell, K.M., Alpers, C., Nordstrom, D., Blum, A., and Williams, A. (2013b) Characterization and remediation of iron (III) oxide-rich scale in a pipeline carrying acid mine drainage at Iron Mountain Mine, California, USA. In International Mine Water Association Symposium, International Mine Water Association, Wendelstein, Germany, pp 45-52.

Challinor, J.M. (2001) Review: the development and applications of thermally assisted hydrolysis and methylation reactions. J Anal Appl Pyrolysis 61:3-34.
Chan, C., Emerson, D., nd Luther, G., III. (2016a) The role of microaerophilic $\mathrm{Fe}$-oxidizing micro-organisms in producing banded iron formations. Geobiology 14:509-528.

Chan, C., McAllister, S., Leavitt, A., Glazer, B., Krepski, S., and Emerson, D. (2016b) The architecture of iron microbial mats reflects the adaptation of chemolithotrophic iron oxidation in freshwater and marine environments. Front Microbiol 7, doi:10.3389/fmicb.2016.00796.

Dworzanski, J.P., Berwald, L., and Meuzelaar, H.L. (1990) Pyrolytic methylation-gas chromatography of whole bacterial cells for rapid profiling of cellular fatty acids. Appl Environ Microbiol 56:1717-1724.

Edwards, K.J., Goebel, B.M., Rodgers, T.M., Schrenk, M.O., Gihring, T.M., Cardona, M.M., Mcguire, M.M., Hamers, R.J., Pace, N.R., and Banfield, J.F. (1999) Geomicrobiology of pyrite $\left(\mathrm{FeS}_{2}\right)$ dissolution: case study at Iron Mountain, California. Geomicrobiol J 16:155-179.

Emerson, D. and Floyd, M.M. (2005) Enrichment and isolation of iron-oxidizing bacteria at neutral pH. Methods Enzymol 397:112-123.

Emerson, D., Fleming, E.J., and McBeth, J.M. (2010) Ironoxidizing bacteria: an environmental and genomic perspective. Annu Rev Microbiol 64:561-583.

Emerson, D., Field, E.K., Chertkov, O., Davenport, K.W., Goodwin, L., Munk, C., Nolan, M., and Woyke, T. (2013) Comparative genomics of freshwater Fe-oxidizing bacteria: implications for physiology, ecology, and systematics. Front Microbiol 4, doi:10.3389/fmicb.2013.00254.

Feirer, N. and Fuqua, C. (2017) Pterin function in bacteria. Pteridines 28:1-14.

Grasset, L., Guignard, C., and Amblès, A. (2002) Free and esterified aliphatic carboxylic acids in humin and humic acids from a peat sample as revealed by pyrolysis with tetramethylammonium hydroxide or tetraethylammonium acetate. Org Geochem 33:181-188.

Grotzinger, J.P., Sumner, D.Y., Kah, L.C., Stack, K., Gupta, S., Edgar, L., Rubin, D., Lewis, K., Schieber, J., Mangold, N., Milliken, R., Conrad, P.G., Des Marais, D., Farmer, J., Siebach, K., Calef, F., Hurowitz, J., McLennan, S.M., Ming, D., Vaniman, D., Crisp, J., Vasavada, A., Edgett, K.S., Malin, M., Blake, D., Gellert, R., Mahaffy, P., Wiens, R.C., Maurice, S., Grant, J.A., Wilson, S., Anderson, R.C., Beegle, L., Arvidson, R., Hallet, B., Sletten, R.S., Rice, M., Bell, J., Griffes, J., Ehlmann, B., Anderson, R.B., Bristow, T.F., Dietrich, W.E., Dromart, G., Eigenbrode, J., Fraeman, A., Hardgrove, C., Herkenhoff, K., Jandura, L., Kocurek, G., Lee, S., Leshin, L.A., Leveille, R., Limonadi, D., Maki, J., McCloskey, S., Meyer, M., Minitti, M., Newsom, H., Oehler, D., Okon, A., Palucis, M., Parker, T., Rowland, S., Schmidt, M., Squyres, S., Steele, A., Stolper, E., Summons, R., Treiman, A., Williams, R., and Yingst, A. (2014) A habitable fluvio-lacustrine environment at Yellowknife Bay, Gale Crater, Mars. Science 343, doi:10.1126/science.1242777.

Havig, J.R., Grettenberger, C., and Hamilton, T.L. (2017) Geochemistry and microbial community composition across a range of acid mine drainage impact and implications for the Neoarchean-Paleoproterozoic transition. J Geophys Res: Biogeosciences 122:1404-1422.

Hays, L.E., Graham, H.V., Des Marais, D.J., Hausrath, E., Horgan, B., McCollom, T.M., Parenteau, M.N., PotterMcIntyre, S.L., Williams, A.J., and Lynch, K.L. (2017) Biosignature preservation and detection in Mars analog environments. Astrobiology 17:363-400.

Ilbert, M. and Bonnefoy, V. (2013) Insight into the evolution of the iron oxidation pathways. Biochim Biophys Acta 1827:161-175. 
Ishida, Y., Wakamatsu, S., Yokoi, H., Ohtani, H., and Tsuge, S. (1999) Compositional analysis of polyunsaturated fatty acid oil by one-step thermally assisted hydrolysis and methylation in the presence of trimethylsulfonium hydroxide. J Anal Appl Pyrolysis 49:267-276.

Jun-Kai, D., Wei, J., Tian-Zhi, Z., Ming, S., Xiao-Guang, Y., and Chui-Chang, F. (1997) The effect of isomerization and degradation of polyunsaturated fatty acids from oils by different volume proportions of tetramethylammonium hydroxide in thermally assisted hydrolysis and methylation. J Anal Appl Pyrolysis 42, doi:10.1016/S0165-2370(96)00976-X.

Kaur, G., Mountain, B.W., Hopmans, E.C., and Pancost, R.D. (2011) Preservation of microbial lipids in geothermal sinters. Astrobiology 11:259-274.

Lalonde, K., Mucci, A., Ouellet, A., and Gelinas, Y. (2012) Preservation of organic matter in sediments promoted by iron. Nature 483:198-200.

Ming, D.W., Archer, P.D., Glavin, D.P., Eigenbrode, J.L., Franz, H.B., Sutter, B., Brunner, A.E., Stern, J.C., Freissinet, C., McAdam, A.C., Mahaffy, P.R., Cabane, M., Coll, P., Campbell, J.L., Atreya, S.K., Niles, P.B., Bell, J.F., Bish, D.L., Brinckerhoff, W.B., Buch, A., Conrad, P.G., Des Marais, D.J., Ehlmann, B.L., Fairén, A.G., Farley, K., Flesch, G.J., Francois, P., Gellert, R., Grant, J.A., Grotzinger, J.P., Gupta, S., Herkenhoff, K.E., Hurowitz, J.A., Leshin, L.A., Lewis, K.W., McLennan, S.M., Miller, K.E., Moersch, J., Morris, R.V., Navarro-González, R., Pavlov, A.A., Perrett, G.M., Pradler, I., Squyres, S.W., Summons, R.E., Steele, A., Stolper, E.M., Sumner, D.Y., Szopa, C., Teinturier, S., Trainer, M.G., Treiman, A.H., Vaniman, D.T., Vasavada, A.R., Webster, C.R., Wray, J.J., and Yingst, R.A. (2014) Volatile and organic compositions of sedimentary rocks in Yellowknife Bay, Gale Crater, Mars. Science 343, doi:10.1126/science.1245267.

Nisshanthini, S.D., Teresa Infanta, S.A.K., Raja, D.S., Natarajan, K., Palaniswamy, M., and Angayarkanni, J. (2015) Spectral characterization of a pteridine derivative from cyanide-utilizing bacterium Bacillus subtilis - JN989651. J Microbiol 53:262-271.

Parenteau, M.N., Jahnke, L.L., Farmer, J.D., and Cady, S.L. (2014) Production and early preservation of lipid biomarkers in iron hot springs. Astrobiology 14:502-521.

Pel, R., Floris, V., and Hoogveld, H. (2004) Analysis of planktonic community structure and trophic interactions using refined isotopic signatures determined by combining fluorescence-activated cell sorting and isotope-ratio mass spectrometry. Freshw Biol 49:546-562.

Potter-McIntyre, S.L., Chan, M.A., and McPherson, B.J. (2014) Textural and mineralogical characteristics and ancient iron (oxyhydr) oxides: terrestrial analogue for sediments in Gale Crater. Astrobiology 14:1-14.

Refojo, P.N., Teixeira, M., and Pereira, M. (2012) The alternative complex III: properties and possible mechanisms for electron transfer and energy conservation. Biochim Biophys Acta 1817:1852-1859.

Roden, E., McBeth, J., Blothe, M., Percak-Dennett, E., Fleming, E., Holyoke, R., Luther, G., and Emerson, D. (2012) The microbial ferrous wheel in a neutral $\mathrm{pH}$ groundwater seep. Front Microbiol 3, doi:10.3389/fmicb.2012.00172.

Shadkami, F. and Helleur, R. (2010) Recent applications in analytical thermochemolysis. J Anal Appl Pyrolysis 89:2-16.

Singer, E., Emerson, D., Webb, E.A., Barco, R.A., Kuenen, J.G., Nelson, W.C., Chan, C.S., Comolli, L.R., Ferriera, S., Johnson, J., Heidelberg, J.F., and Edwards, K.J. (2011) Mariprofundus ferrooxydans PV-1 the first genome of a marine Fe(II) oxidizing Zetaproteobacterium. PLoS One 6, doi:10.1371/journal.pone.0025386.

Summons, R.E., Brassell, S.C., Eglinton, G., Evans, E., Horodyski, R.J., Robinson, N., and Ward, D.M. (1988) Distinctive hydrocarbon biomarkers from fossiliferous sediment of the late Proterozoic Walcott Member, Chuar Group, Grand Canyon, Arizona. Geochim Cosmochim Acta 52:2625-2637.

Sumner, D.Y. (2004) Poor preservation potential of organics in Meridiani Planum hematite-bearing sedimentary rocks. $J$ Geophys Res: Planets 109, doi:10.1029/2004JE002321.

Vesenka, J., Havu, J., Hruby, D., and Emerson, D. (2018) A model for sheath formation coupled to motility in Leptothrix ochracea. Geomicrobiol J 35:366-374.

Wilhelm, M.B., Davila, A.F., Eigenbrode, J.L., Parenteau, M.N., Jahnke, L.L., Liu, X., Summons, R.E., Wray, J.J., Stamos, B.N., O'Reilly, S.S., and Williams, A.J. (2017) Xeropreservation of functionalized lipid biomarkers in hyperarid soils in the Atacama Desert. Org Geochem 103:97-104.

Williams, A.J., Sumner, D.Y., Alpers, C.N., Karunatillake, S., and Hofmann, B.A. (2015) Preserved filamentous microbial biosignatures in the Brick Flat gossan, Iron Mountain, California. Astrobiology 15:637-668.

Williams, A.J., Alpers, C., Sumner, D., and Campbell, K. (2017a) Filamentous hydrous ferric oxide biosignatures in a pipeline carrying acid mine drainage at Iron Mountain Mine, California. Geomicrobiol J 34:193-206.

Williams, A.J., Eigenbrode, J., Johnson, S., Craft, K., Wilhelm, M., O'Reilly, S., Summons, R., Benison, K., and Mahaffy, P. (2017b) Fatty acid detection in Mars-analogous rock samples with the wet chemistry experiment on the Sample Analysis at Mars (SAM) instrument [abstract 3071]. In Astrobiology Science Conference 2017, Lunar and Planetary Institute, Houston.

Yamauchi, K., Tanabe, T., and Kinoshita, M. (1979) Trimethylsufonium hydroxide: a new methylating agent. $J$ Org Chem 44:638-639.

Address correspondence to: Melissa A. Merrill Floyd NASA Goddard Space Flight Center, code 699 8800 Greenbelt Road B33, B206 Greenbelt, MD 20771-0003

E-mail: melissa.floyd@nasa.gov

Submitted 17 August 2017 Accepted 22 May 2018

$\begin{aligned} & \quad \text { Abbreviations Used } \\ & \mathrm{AC}=\text { alternative complex } \\ & \mathrm{AMD}=\text { acid mine drainage } \\ & \mathrm{CPS}=\text { counts per second } \\ & \mathrm{FeOB}=\text { Fe-oxidizing bacteria } \\ & \mathrm{GC}-\mathrm{MS}= \text { gas chromatography-mass spectrometry } \\ & \mathrm{GTP}=\text { guanosine triphosphate } \\ & \mathrm{NCMA}= \text { National Center for Marine Algae and } \\ & \text { Microbiota } \\ & \mathrm{TDU}=\text { thermal desorption unit } \\ & \mathrm{THM}=\text { thermally assisted hydrolysis and } \\ & \text { methylation } \\ & \mathrm{TMAH}=\text { tetramethylammonium hydroxide } \\ & \mathrm{TMSH}=\text { trimethylsulfonium hydroxide }\end{aligned}$

